Erratum

\title{
Erratum to "Counteraction of HCV-Induced Oxidative Stress Concurs to Establish Chronic Infection in Liver Cell Cultures"
}

\author{
Simona Anticoli (D, ${ }^{1,2}$ Donatella Amatore, ${ }^{2}$ Paola Matarrese, ${ }^{1}$ Marta De Angelis, ${ }^{2}$ \\ Anna Teresa Palamara $\left(\mathbb{D},{ }^{2,3}\right.$ Lucia Nencioni $\left(\mathbb{0},{ }^{2}\right.$ and Anna Ruggieri $\left(\mathbb{C}^{1}\right.$ \\ ${ }^{1}$ Istituto Superiore di Sanità, Center for Gender-Specific Medicine, Rome, Italy \\ ${ }^{2}$ Department of Public Health and Infectious Diseases, Istituto Pasteur Italia-Fondazione Cenci-Bolognetti, \\ Sapienza University of Rome, Italy \\ ${ }^{3}$ IRCSS San Raffaele Pisana, Department of Human Sciences and Promotion of the Quality of the Life, San Raffaele Open University, \\ Rome, Italy
}

Correspondence should be addressed to Anna Ruggieri; anna.ruggieri@iss.it

Received 28 March 2019; Accepted 2 April 2019; Published 18 April 2019

Copyright (C) 2019 Simona Anticoli et al. This is an open access article distributed under the Creative Commons Attribution License, which permits unrestricted use, distribution, and reproduction in any medium, provided the original work is properly cited.

In the article titled "Counteraction of HCV-Induced Oxidative Stress Concurs to Establish Chronic Infection in Liver Cell Cultures" [1], there was an error in the Authors' Contributions section. Therefore, the section should be corrected as follows:

S. Anticoli and D. Amatore equally contributed to the execution of the experiments and drafted the paper; A. Ruggieri and L. Nencioni equally contributed to conceiving the idea, designed the study, participated to the analysis and interpretation of data, and supervised the manuscript; M. De Angelis was in charge of western blotting experiments; P. Matarrese was in charge of the flow cytometry experimental analysis and interpretation of the resulting data; AT Palamara was the overall supervisor.

\section{References}

[1] S. Anticoli, D. Amatore, P. Matarrese et al., "Counteraction of HCV-induced oxidative stress concurs to establish chronic infection in liver cell cultures," Oxidative Medicine and Cellular Longevity, vol. 2019, Article ID 6452390, 14 pages, 2019. 


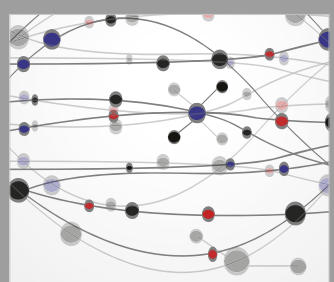

The Scientific World Journal
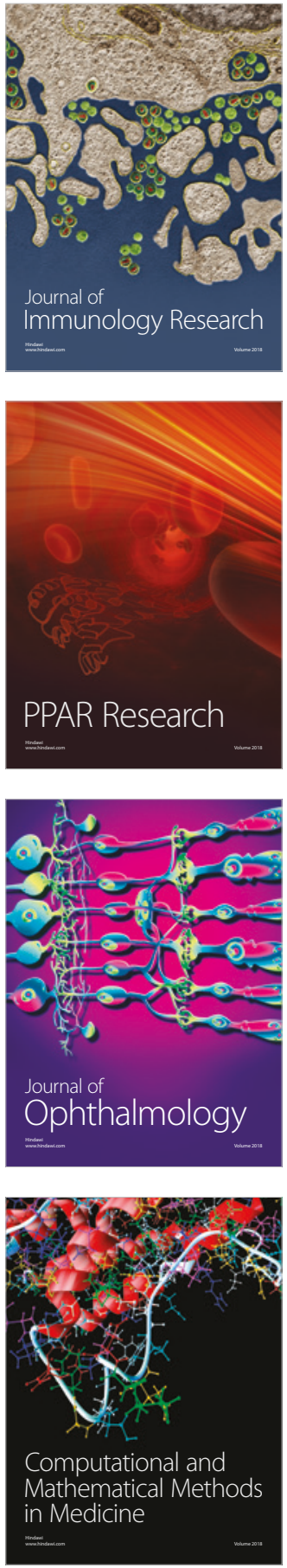

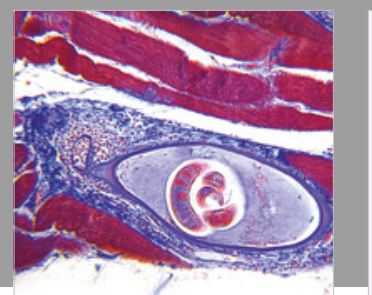

Gastroenterology Research and Practice

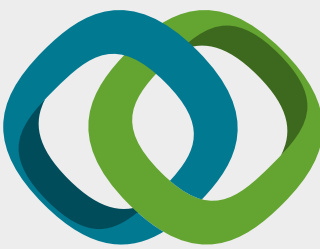

\section{Hindawi}

Submit your manuscripts at

www.hindawi.com
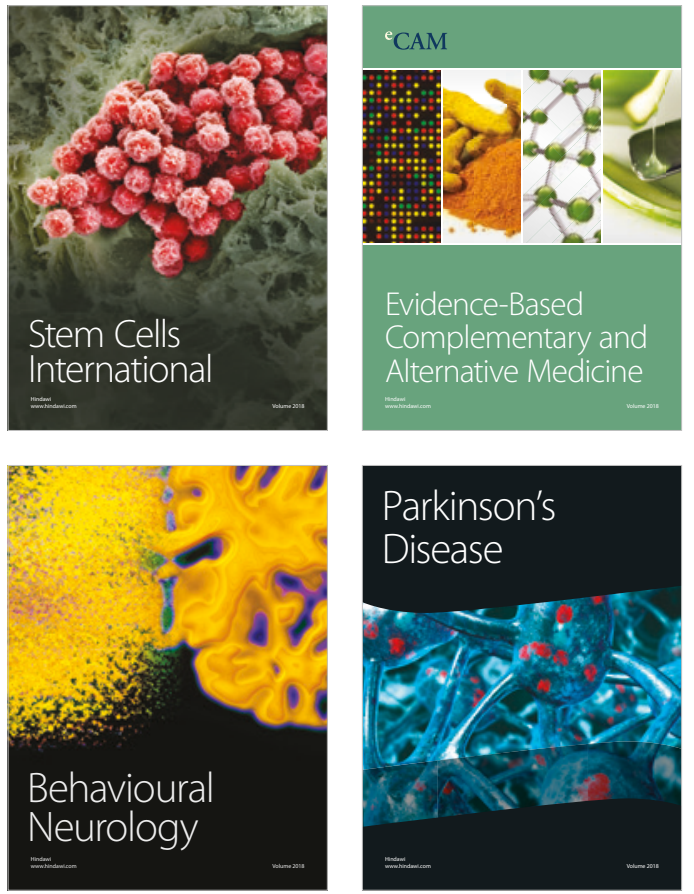

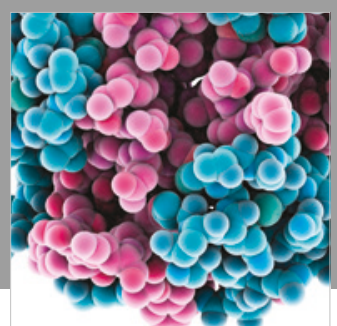

ournal of

Diabetes Research

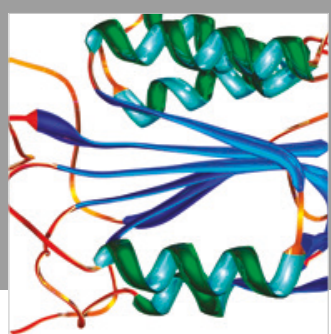

Disease Markers
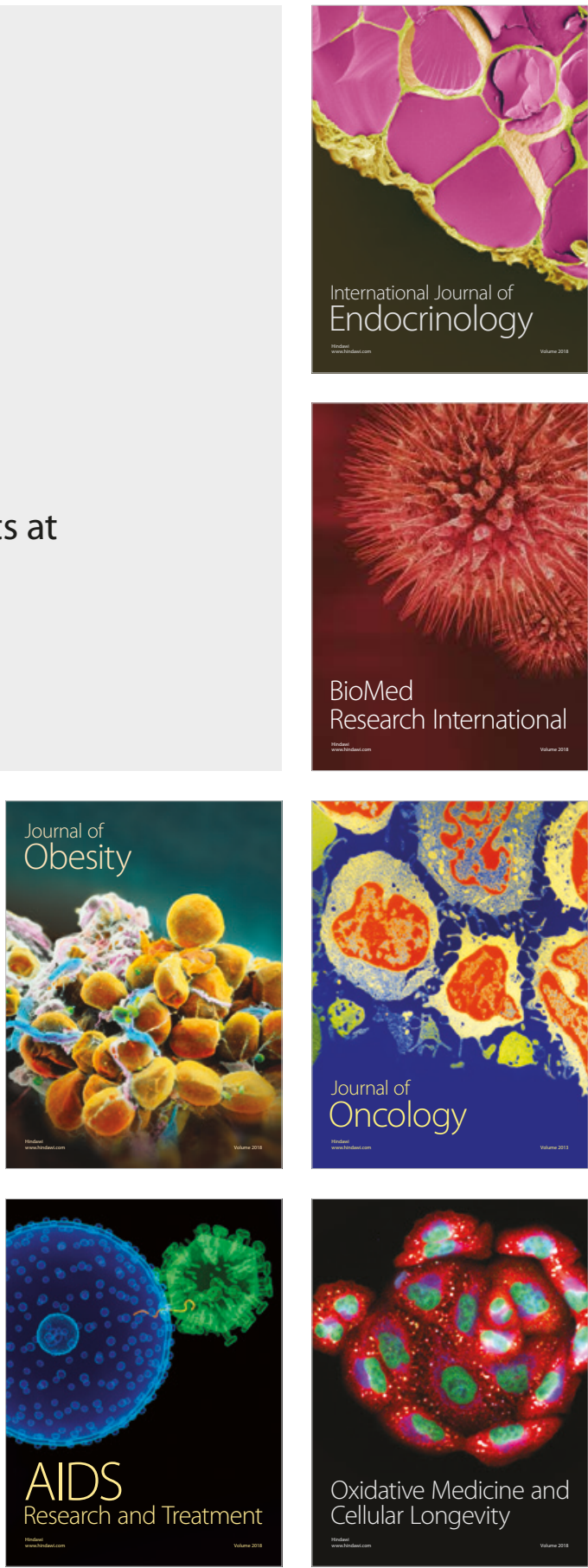